\title{
Prevalence and Determinants of Smoking Among Adolescent Boys in Dhaka City
}

\author{
MM Khan ${ }^{1}$, MR Karim², MS Alam³ ${ }^{3}$ MM Ali ${ }^{4}$, JHB Masud ${ }^{5 *}$
}

\begin{abstract}
Background: Smoking is recognized as a major public health problem in the world.

Materials \& Methods: The objective of the study was to assess the prevalence and determinant of adolescent smoking in West Kafrul Dhaka. This was a cross sectional study conducted in 2013 among 150 adolescent boys of school and slum.

Results: The results showed $35.33 \%$ adolescent boys had smoking habit. Most of the adolescent (86.79\%) had started smoking when they were 14-17 years old. This study found that peers influence (50.94\%) was the most common causes of smoking. Among the boys who live in slum, $80 \%$ were smoker and among the school going boys $15 \%$ were smoker.

Conclusion: Smoking was very common among middle-class male teenagers and even more prevalent among youths from nearby slums. Awareness program on tobacco will be an effective way to control.
\end{abstract}

Key Words: Smoking, Adolescent boys

\section{Introduction}

Smoking is the major single known cause of noncommunicable diseases, such as cancer and cardiovascular diseases. A study of Giovino found that most people try their first cigarette and become daily smokers as adolescents. ${ }^{1}$ Kuper reported his study the people who start smoking before 15 years of age have double the risk of developing lung cancer than those who start after the age of 20 years. ${ }^{2}$ Smoking is a risk factor for mortality from several medical causes. Cigarette smoking and exposure to tobacco smoke are associated with premature death, economic losses to society, and a substantial burden on the health-care system. Smoking is the primary causal factor for at least $30 \%$ of all cancer deaths, for nearly $80 \%$ of deaths from chronic obstructive pulmonary disease (COPD), and for early cardiovascular disease and deaths. Smoking harms nearly every organ of human body, causing many diseases and reducing the health in general. Cigarette smoking is associated with a tenfold increase in the risk of dying from chronic obstructive lung disease. About $90 \%$ of all deaths from chronic obstructive lung diseases are attributable to cigarette smoking. Cigarette smoking has many adverse reproductive and early childhood effects, including an increased risk for infertility, preterm delivery, stillbirth, low birth weight, and sudden infant death syndrome (SIDS). ${ }^{3}$ People with smoking habit are more likely to develop chronic bronchitis (OR $=6.92,95 \% \mathrm{CI}$ 4.22 to 11.36$){ }^{4}$

Secondhand smoke, also known as environmental tobacco smoke (ETS), is a mixture of the smoke given off by the burning end of a cigarette, pipe or cigar and the smoke exhaled from the lungs of smokers. Secondhand smoke increases the risk of coronary heart disease by $30 \%$. This effect is larger than one would expect on the basis of the risks associated with active smoking and the relative doses of tobacco smoke delivered to smokers and nonsmokers. The effects of even brief (minutes to

1Md. MH Khan, Upazila Health Complex, Gosairhat, Shariatpur, Bangladesh

2Md. R Karim, Training \& Assistance for Health \& Nutrition (TAHN) Foundation, Bangladesh

${ }^{3}$ Md. S Alam, Jayson Natural Products Ltd, JAYSON Group, Bangladesh

${ }^{4}$ Md. M Ali, IBN SINA Pharmaceutical Industry Limited, Bangladesh

5 Jakir H B Masud, Public Health Informatics Foundation (PHIF), Bangladesh

*Corresponding author

Date of submission: 31.07.2017, Date of acceptance: 11.10.2017

AKMMC J 2018; 9(1) : 34-38 
hours) passive smoking are often nearly as large (averaging $80 \%$ to $90 \%$ ) as chronic active smoking. ${ }^{5}$

The decline of tobacco smoking observed in developed countries, however, is not evident in many developing countries including Bangladesh. Despite the high level of poverty in Bangladesh, smoking rates are relatively high and smoking prevalence is the highest among the poorest. Prevalence of smoking declines proportionally as income increases. A very little is known about the pattern and prevalence of smoking in general and specifically among the young adults, who are the target of the ever expanding tobacco market. In developed countries, almost $80 \%$ initiate their smoking start at a younger age. In developing countries, it happens by late adolescence, but it is observed that the age of initiation is becoming lower. For example, in Indonesia, $10 \%$ of smokers had started when aged 10-14 years, and 59\% when they were 15-19 years old. It is also observed that prevalence of smoking among male aged 15-19 years increased from $4 \%$ in 1995 to $24 \%$ in 2001.6

The principal predictors of smoking among the adolescents are parental household influence, peer pro-smoking influence and environmental predisposition. The peer group includes sibling and friends. It is also found that age, socio-cultural status, level of education and racial differences all affect smoking initiation by teenagers. The association between greater educational attainment and decreased smoking is observed in more developed countries. In several countries where multiethnic society exists, it is observed that acculturation is strongly associated with smoking initiation. In some studies, the age of initiation of smoking is found less than 15 years and male sex is more likely to smoke at an earlier age. ${ }^{7}$ This study investigated prevalence and determinates smoking behavior among adolescent boys in West Kafrul under Dhaka city with to analyze the impact of socio-economic, demographic, cultural and environmental factors for initiation and continuation of smoking behavior among adolescents.

\section{Method}

A cross sectional descriptive study was conducted among adolescent boys in West Kafrul of Dhaka city. The study was conducted at Agargoun Taltola Sorkari
Colony High school and Women College, Taltola, Adorsho Ucho Biddaloy Taltola and Boddar Basti (Slum area of West Kafrul) in Dhaka city. The duration of the study was 6 months from January 2013 to June 2013. The sample size was 150 adolescent boys for this study and out of them 50 from slum boys and 100 from school going boys. Purposive sampling method was used to select sample population from adolescent at selected schools and slums who live in west Kafrul in Dhaka city. Data were analyzed using SPSS (version 16). Ethical approval was obtained from review committee of the ASA University of Bangladesh.

\section{Results}

A cross sectional descriptive study was conducted to find out the prevalence and determinants of smoking among adolescent boys.

Table-1: Distribution of the socio-demographic characteristics of respondents

\begin{tabular}{lcc}
\hline Socio-demographic characteristics & Frequency (n) & Percentage (\%) \\
\hline Age of respondent & & \\
10-13 years & 61 & $40.7 \%$ \\
14-17 years & 67 & $44.7 \%$ \\
18-19years & 22 & $14.6 \%$ \\
Religion & & \\
Hindu & 8 & $5.3 \%$ \\
Islam & 142 & $94.7 \%$ \\
Residential condition & & \\
Multi storied building & 100 & $66.7 \%$ \\
Slum & 50 & $33.3 \%$ \\
Educational status & & \\
Illiterate & 7 & $4.7 \%$ \\
Literate & 11 & $7.3 \%$ \\
Primary & 24 & $16.0 \%$ \\
Secondary & 108 & $72.0 \%$ \\
\hline
\end{tabular}

Table-2: Distribution of the respondents by causes of initiating smoking

\begin{tabular}{lcc}
\hline Causes of smoking & Frequency $(\mathbf{n})$ & Percentage (\%) \\
\hline Watching TV/Cinema & 2 & 3.8 \\
Peer influence & 27 & 50.9 \\
Family influence & 7 & 13.2 \\
To feel mature & 4 & 7.5 \\
Poor performance in class & 1 & 1.9 \\
To follow senior in locality & 5 & 9.4 \\
To attract girl & 7 & 13.2 \\
\hline
\end{tabular}


Table-3: Distribution of respondents' knowledge about the effect of smoking

\begin{tabular}{lcc}
\hline $\begin{array}{l}\text { Knowledge about the effect of } \\
\text { smoking }\end{array}$ & $\begin{array}{c}\text { Frequency (n) Percentage } \\
(\%)\end{array}$ \\
\hline Harmful & 150 & $100 \%$ \\
Not harmful & 0 & $0 \%$ \\
\hline
\end{tabular}

Table-4: Distribution of respondents by source of learning about effect of smoking

\begin{tabular}{lcc}
\hline $\begin{array}{l}\text { how learned about } \\
\text { effect of smoking }\end{array}$ & $\begin{array}{c}\text { Frequency (n) } \\
86\end{array}$ & $\begin{array}{c}\text { Percentage } \\
\mathbf{( \% )}\end{array}$ \\
\hline School & 64 & $58 \%$ \\
Mass Media & & $42 \%$ \\
\hline
\end{tabular}

Table-5: Distribution of respondent by interest in quitting smoking

\begin{tabular}{lcc}
\hline $\begin{array}{l}\text { Respondent who } \\
\text { want to quit }\end{array}$ & $\begin{array}{c}\text { Frequency (n) } \\
\text { Yes }\end{array}$ & $\begin{array}{c}\text { Percentage } \\
\mathbf{( \% )}\end{array}$ \\
\hline No & 47 & 86.4 \\
\hline
\end{tabular}

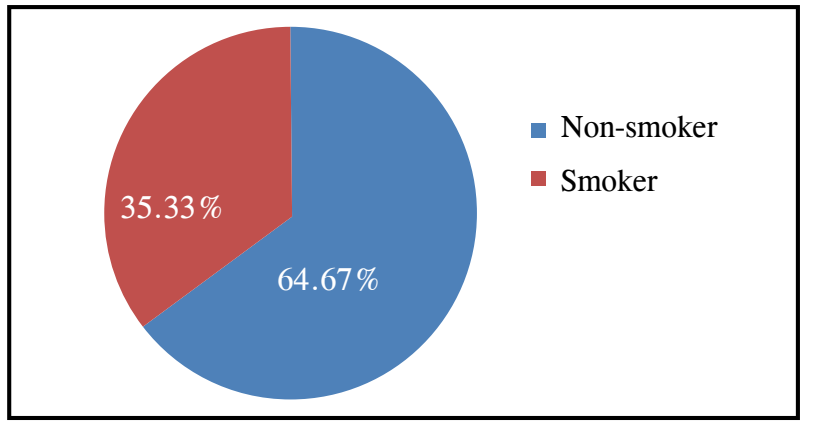

Figure-1: Distribution of the smoking status of respondents

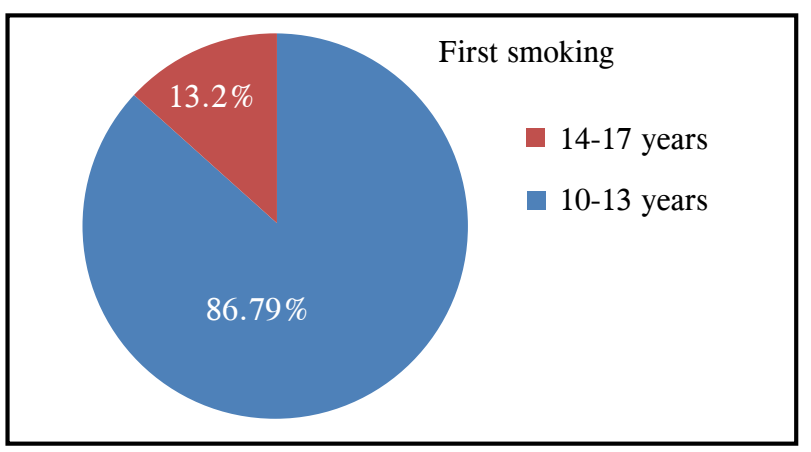

Figure-2: Distribution of respondents by age at first smoking
Most of the respondents $(44.7 \%)$ of this study were in 14-17 years age group. Mean age of the respondents was 14.31 years. Among the respondents $66.7 \%$ lived in multi storied building, $33.3 \%$ lived in slum area. Most of the respondents $72.0 \%$ were studying in secondary education level (Table 1).

Majority $50.94 \%$ respondents who had addiction in smoking started smoking due to peer influence (Table 2). The entire adolescent knows about the effect of smoking (Table 3).Most of the respondents $58 \%$ learned about the effect of smoking from schools and $42 \%$ adolescent learned from mass media (Table 4). Most of the respondents $86.4 \%$ had made an attempt to quit smoking (Table 5).

Among the respondents $35.33 \%$ had smoking habit (Figure 1). Most of the adolescent $(86.79 \%$ ) had started smoking when they were 14-17 years old (Figure 2).

\section{Discussion}

In this study we found the prevalence of adolescent smoking was $35.33 \%$. The results showed $35.33 \%$ boys had smoking habit which is similar with adolescent smoking scenario of south east Asia where they found $15-30 \%$ adolescent had prevalence with smoking. ${ }^{8} \mathrm{We}$ found that most of the adolescent $86.79 \%$ started smoking when they were 14-17 years old which is similar with previous study conducted by Habibul Ahsan and his associates, they found $68 \%$ of the slum dwellers in Dhaka city were regular smokers. ${ }^{9}$ And this study shows $13.21 \%$ were started smoking in early stage at 10 13 age group which is similar with adolescent smoking age of Indonesia where $10 \%$ of smokers had started when aged 10-14 years. ${ }^{8}$

In this study we found more than $80 \%$ slum boys was used to smoking which is similar with previous study. In their study they found $69 \%$ of slum boys had smoking. 9 We found $15 \%$ of school going boys was habitual with smoking this similar with WHO adolescent smoking scenario south eastern area which is $15-25 \% .^{8}$

In this study we found most of adolescent (50.94 \%) started smoking due to peer's influence. We also found there was strong relationship in between smoking and adolescent smoking Which is similar 
with previous study conducted by Habibul Ahsan and his associates while that study suggests both groups of smokers had been influenced to take up smoking by the smoking behavior of peers and parents, peers were more important for the students 9 another study found that children from smoking families are more likely to choose smoking friends. ${ }^{10}$

In our study we saw among the adolescent boys $13.2 \%$ had started smoking due to adolescent felt smoking may helps to attract the girls, $9.4 \%$ follow the senior of the locality, $7.5 \%$ feel mature enough. A study of Fidler and his associates proved that, relationship between dating and smoking uptake among English school children has also been found being an early "dater" strongly predicts smoking uptake. ${ }^{11}$ In this study $13.2 \%$ smoking boys inspired by family smoking prevalence. In previous study it was found that, within a family, a strong association of both parents and older siblings smoking with child's smoking initiation and regular smoking has been documented in a large number of cross sectional as well as in longitudinal studies. ${ }^{12,13}$ The influence of older siblings smoking has been less studied but their influence has been found to be substantial in adolescence. ${ }^{14}$

Adolescent were not directly interested to cigarette company advertisement because direct advertisement is prohibited in our country. But they were interested in adolescent smoking due to watching TV/Cinema. In our study $3.8 \%$ were influenced to watching smoking in cinema and Television. Another study was done about Effect of viewing smoking in movies on adolescent smoking initiation: a cohort study they found that there was strong evidence that viewing smoking in movies promotes smoking initiation among adolescents. ${ }^{15}$

In school, teachers may not able to take care the students who continuously performing poor in the class as a result they went to depressed. In our Study we found $2 \%$ of adolescent smoker start smoking due to poor performance in the class. Simons and his associates found Smoking among adolescents association with problems at school. ${ }^{16}$

\section{Conclusion}

Our study suggests that such factors should be taken into account when designing effective tobacco control programs among adolescent boys in urban area. This is an effort which has been done to reduce tobacco consumption among adolescent boys and introduce awareness programs to amend their health risk behavior. There is a need to implement public health interventions, with special attention to the determinants of smoking in this age group.

\section{Conflict of interest: None}

\section{Reference}

1. Giovino, G.A. Epidemiology of Tobacco Use in the United States. Oncogene 2002; 21: 73267340 .

2. Kuper, H., Adami, H.O., Boffetta, P. Tobacco Use, Cancer Causation and Public Health Impact. JInt Med 2002; 251: 455-466

3. Center for Disease Control and Prevention (CDC2008). Health Effects of Cigarette Smoking. Smoking and Tobacco use, Fact sheet. http:// www.cdc.gov/ tobacco/ data_statistics/ fact_sheets/ health_effects/ health_effects.htm

4. Menezes, et al. Prevalence and risk factors for chronic bronchitis in Pelotas, RS, Brazil: a population-based study. PubMed Central, Thorax. 1994 December; 49(12): 1217-1221.

5. Barnoya and Glantz. Cardiovascular Effects of Secondhand Smoke: Nearly as Large as Smoking. Journal of American Heart Association; Circulation 2002; 111: 2684-2698

6. Mohammad Y. Craving for Nicotine, 2001: A study on Tobacco Prevalence in Bangladesh. Bangladesh Institute of development studies, 2001.

7. Sen U. and Basu A, Analysis of factors influencing an adolescents intention to be a no smoker; Cittaranjan National Cancer Institute, Calcutta, India, May 2000 
8. WHO World Health Organization. Smoking report WPR. http:/ /www. wpro.who.int/ health_topics/tobacco/

9. Habibul Ahsan, Peter Underwood, David Atkinson, 1998:Smoking among Male Teenagers in Dhaka, Bangladesh, Preventive Medicine, Volume 27, Issue 1, January 1998, Pages 70-76

10. Engels RCME and Willemsen M: Communication about smoking in Dutch families: associations between anti-smoking socialization and adolescent smoking related cognitions. Health Educ Res 2004; 13: 227-238.

11. Fidler JA, West R, Jarvis MJ and Wardle J. Early dating predicts smoking during adolescence: a prospective study. Addiction 2004; 101: 1805-1813

12. Vink JM, Willemsen G and Boomsma DI. The association of current smoking behavior with the smoking behavior of parents, siblings, friends and spouses. Addiction 2003; 98: 923-931
13. Rajan KB, Leroux BG, Peterson AV Jr, et al. Nine-year prospective association between older siblings' smoking and children's daily smoking. J Adolesc Health 2003; 33: 25-30.

14. Hibell B, Andersson B, Bjarnason T, et al. The ESPAD report 2003. Alcohol and other drug use among students in 35 European countries. The Swedish Council for Information on Alcohol and Other Drugs (CAN) and the Pompidou Group at the Council of Europe. Stockholm. Sweden 2004.

15. A Dalton. Effect of viewing smoking in movies on adolescent smoking initiation: a cohort study, The Lancet 2003; 362(9380): 281 - 285.

16. Simons-Morton BG, Crump AD, Haynie DL, et al. Psychosocial, school and parent factors associated with recent smoking among early -adolescent boys and girls. Prev Med 1999; 28: 138-148. 